\title{
As Independências do Brasil: ponderações teóricas em perspectiva historiográfica
}

Jurandir MALERBA ${ }^{1}$

\begin{abstract}
RESUMO: $O$ tema da Independência do Brasil produziu verdadeiras linhagens historiográficas ao longo de quase dois séculos. Este ensaio visa a sublinhar a característica fundamental da historiografia que é sua própria historicidade, por meio de um exercício comparativo entre os quadros teóricos de interpretação histórica vigentes há três décadas e os que vigoram hoje em dia.

PALAVRAS-CHAVE: Independência - Brasil; Independência Historiografia; Teoria da Historiografia.
\end{abstract}

Em um seminário que tive o privilégio de organizar em 2003, chamado "New Approaches to Brazilian Historiography", junto ao Centre for Brazilian Studies da Universidade de Oxford, começaram a se desenhar algumas das questões que pretendo desenvolver a seguir. Para aquela ocasião, eu havia preparado um paper de abertura, onde fazia um balanço da historiografia da Independência nos últimos 25 anos - desde 1980 para cá.

Afirmei, naquela oportunidade, que as questões que hoje levantam os historiadores da Independência do Brasil são virtualmente as mesmas que se levantaram nos últimos 180 anos, questões que as diversas gerações de historiadores, com maior ou menor sucesso, responderam a seu modo. A recente vaga revisionista da história da Independência está aí a demonstrar que nem tudo é consenso no que concerne a temas os mais visitados pela historiografia, relativos à questão de por que, afinal de contas, sucedeu-se a independência do Brasil de Portugal. À medida que se qualifica o debate, percebe-se a recorrência de diferentes perspectivas do objeto, índices das preocupações, interesses e habilidades de cada geração de historiadores. Entre essas questões eu destacava: 
- Qual ou quais fatores, forças, processos, atores conduziram ao desfecho da emancipação política?

- Teria havido algum projeto "nacional" fundamentando o movimento?

- Havia algum tipo de unidade na América de colonização portuguesa à época da Independência?

- Quais as periodizações mais consistentes produzidas pela historiografia?

- A vinda da corte para o Rio de Janeiro terá protelado ou deflagrado a Independência?

- Que tipo de relação a Independência guarda com os movimentos insurrecionais do final do XVIII?

- Qual o caráter da Independência: conservadora, reformista ou revolucionária?

- Quais foram os efeitos da crise do antigo sistema colonial no processo de Independência?

- Que peso atribuir, igualmente, às radicais transformações culturais - ou civilizacionais - geradas com a abertura de 1808 e 0 afluxo de levas de migrantes de todos os pontos?

- O que há de ruptura e o que há de continuidade no processo de Independência?

- Qual o caráter dos movimentos insurreicionais que ocorreram nos anos da Independência?

- Qual o papel desempenhado por partidos e ideologias?

- Quais a relações do movimento de restauração de 1820 em Portugal com a Independência?

- Qual o papel desempenhado pelo rei e sua casa dinástica?

- Que peso atribuir à ação de grupos organizados, como a maçonaria, por exemplo?

- Como se deu a participação popular no movimento de independência?

- Como agiram ou reagiram os grupos sociais nas diferentes províncias?

Essas questões, muitas delas tão antigas como o próprio acontecimento que elas procuram explicar, ocupam grande parte 
dos historiadores da Independência até hoje. "Independência do Brasil". Não vou retomar aqui as calorosas discussões que animaram aquelas inesquecíveis tardes de maio do ameno verão inglês. Minhas problematizações tentavam seguir o passo da própria historiografia. Independência do Brasil: termo composto, partes ambíguas.

O quê, quando, "Independência"?

Onde, quem "do Brasil"?

Aqueles que buscam responder a essas questões provocativas acabam desaguando diretamente nos impasses e diferentes soluções interpretativas postas na mesa pela historiografia competente. A primeira remete ao problema central da precedência ou não de algo como uma "nação", ainda que embrionária, ou "sentimento nacional", mesmo que tímido, que tivesse motivado os "brasileiros" na peleja por sua autonomia perante a metrópole. Esta primeira imediatamente reclama a segunda questão: mas o que era o Brasil? Quem os "brasileiros"? Aí, o problema da unidade (ou não) da América Portuguesa e da identidade (social, racial, cultural?) de seus habitantes. M as vou manter o juízo para não cair na tentação de querer resgatar aqui essas questões, muito menos de ousar respondêlas.

0 que me veio tilintando na mente desde o seminário - e muito em função das reflexões teóricas que venho avançando em projetos editoriais e na prática docente - é o fato de que, sim, muitas dessas questões, respondidas distintamente a cada geração (e distintamente dentro de uma mesma geração) são antigas, foram levantadas há muito tempo e respondidas a seu modo a cada momento. Mas, este é o ponto, outras questões não estiveram sempre na mesa. São novas, inéditas - 0 que não implica, necessariamente, que sejam mais ou menos importantes do que as vel has questões consagradas.

E por que isso acontece? Hoje eu vou fazer um exercício despretensioso, um pensar em voz alta nessa propriedade da historiografia, nesse seu caráter fundamental que é sua própria historicidade. E vou fazer isso por meio da comparação de duas obras bastante similares em seu escopo, mas já bem diversas quanto a seus conteúdos. Vou comparar a clássica coletânea 
organizada pelo Prof. Carlos Guilherme M ota (1822: dimensões), com a obra coletiva que estou organizando a partir das discussões que começaram em Oxford, em vias de publicação. ${ }^{3}$

\section{2: DIMENSÕES}

Nada mais oportuno do que uma efeméride para se promover um ou se inserir num debate. No caso, as comemorações do "Sesquicentenário da Independência" deram ensejo à publicação de uma verdadeira avalanche de obras sobre a Independência, entre as quais uma que logrou alcançar merecida fortuna crítica. 0 Prof. Carlos Guilherme M ota reuniu contribuições dele e de outros dezessete renomados colaboradores para apresentar o estado da arte no que tange ao debate histórico-historiográfico sobre a Independência àquela altura.

Depois dos "Preliminares à discussão", o organizador agrupou os ensaios em dois níveis: "Das dependências" e "Das Independências". O primeiro, de escopo geral, onde, "... ao lado de indagação mais teórica, ficam indicados alguns mecanismos de passagem do Antigo sistema colonial para o sistema mundial de dependências, permitindo discutir, tanto do lado europeu como do brasileiro, o significado de 1822".

N esse primeiro grupo estão os ensaios de Fernando N ovais sobre "As dimensões da Independência", de J. Godechot ("Independência do Brasil e Revolução do Ocidente), de F. Mauro sobre a conjuntura atlântica, de Joel Serrão sobre a inserção de Portugal nela, sobre europeus no Brasil (Mota) e brasileiros nas cortes constituintes (Fernando Thomaz) e, ainda, os ensaios clássicos de Emilia Viotti da Costa sobre Bonifácio, e de M aria O dila Dias sobre a "interiorização da metrópole".

O segundo "nível", sempre de acordo com o organizador, seria "mais localizado", perscrutando as nuances regionais de enfrentamento da Independência nas várias partes do Brasil. Aqui, quase que num lamento, Prof. M ota diz que a abordagem se torna inevitavelmente événementielle, embora os autores não descurem da consideração de "processos maiores em que se 
articulam as diversas regiões", pois sabem que, "em história, os eventos não podem ser analisados desvinculados de sistemas, de estruturas, de processos". ${ }^{4}$ Neste "segundo nível" de análise incluem-se ensaios sobre o processo de Independência nas diversas regiões ou mesmo províncias (Norte e Nordeste são abordados no atacado; Bahia, Goiás, M inas, Rio, São Paulo e Rio Grande do Sul, no varejo).

Podemos ficar mais al guns instantes nessas "preliminares às dimensões", para tentar resgatar o sentido intelectual das problemáticas que aqueles historiadores elevavam como prioridades. Citando Eduardo D'Oliveira França, Prof. M ota reclamava a ausência de estudos "não tradicionais", desde os de demografia histórica até "investigações na esfera das formações ideológicas". Citando M ota:

Mais do que isso, apontava o Professor Oliveira França, a dificuldade em formular, com propósito, questões verdadeiramente substantivas para inspirar trabalhos monográficos e para fugir à linha do ingênuo (p.10)

M as o que seriam, então, "questões substantivas"? Fica claro que não aquelas "tradicionais", presas aos documentos oficiais e às questões de Estado, características indeléveis da nefanda história "positivista" ou "historizante", que sucessivas gerações de historiadores, guiados pela campanha implacável movida por Lucien Febvre na primeira metade do século XX, procuraram detratar. Naquele quadrante, onde, no Brasil, a construção de uma história estrutural, explicativa, que buscava responder aos porquês dos eventos com base em fundamentação teórica rigorosa, ainda era um horizonte a ser buscado, Prof. M ota deixa entender que o anseio fundador do projeto de sua coletânea era responder ao desafio do velho mestre. Reclamava do atraso dos historiadores em aceitar acriticamente a Independência, num momento em que sociólogos, economistas e cientistas sociais buscavam construir as teorias da dependência. Aquele quadrante, virada da década de 1970, corresponde ao auge da repercussão mundial daquelas teorias, que constituíram a mais genuína contribuição dos pensadores latino-americanos ao 
debate sobre a trajetória e a situação da América Latina no sistema econômico mundial. Para o Prof. Mota, portanto, a marca da historiografia da Independência naquela conjuntura era o atraso, o pouco avanço científico de que até então padecia um dos temas mais importantes da história do Brasil.

E quais questões mereceriam ser respondidas para se alterar tal quadro? Ao responder a esta pergunta, Prof. M ota nos dá a conhecer, parafraseando Lucien Goldman, o nível de consciência científica possível à época:

$\mathrm{Na}$ verdade, o sentido da história do Brasil nesse período [da Independência] não pode ser dissociado de processos mais abrangentes que a historiografia contemporânea significa e ordena sob o rótulo 'do feudalismo ao capitalismo'. Parece certo que a lenta transição do feudalismo ao capitalismo na Europa teve como contrapartida, em certas áreas do mundo colonial, a passagem do Antigo Sistema Colonial para o sistema mundial de dependências. [...] Por outro lado, problemas complexos podem se apresentar, como o da definição da sociedade colonial, cuja estruturação explicará o predomínio das persistências, mais que 0 das mudanças no período subseqüente.

Em outras palavras, a questão da Independência, da ruptura, da mudança, enfim, do devir, élhe menos importante, ou se encontra subordinada aos imperativos das permanências, das persistências, das continuidades, das estruturas. Trata-se de uma concepção flagrantemente inspirada no marxismo e na melhor tradição braudeliana dos Annales. Dessa concepção eminentemente estrutural derivavam as indagações que Prof. M ota elegia como as prioridades a serem resolvidas.

0 primeiro ensaio da primeira seção ("Das dependências") e, por conseguinte, da coletânea, intitula-se "As dimensões da Independência", que sintomaticamente batiza o próprio livro. N ele, Prof. Fernando N ovais vai estabelecer a linha interpretativa geral do conjunto da obra, aquilo que Novais concebe como 0 "sentido da Independência". A idéia geral é a de que a Independência do Brasil só pode ser entendida se e quando inserida no contexto mundial da transição do feudalismo ao capitalismo, onde a "crise do antigo sistema colonial" é o ponto 
culminante do processo de acumulação primitiva que permitiu 0 surgimento do capitalismo na Europa, mercê da exploração colonial da época moderna. A história da Independência do Brasil tem que derivar desse outro macroprocesso. E ponto. Esta tese é reiterada por ambos os autores num livro que escreveram conjuntamente em 1985, chamado exatamente A Independência política do Brasil. Vou deixar por um momento a coletânea e seguir seu raciocínio a partir deste livro, pois que ali sua tese se apresenta mais explicitamente e em maior detalhe.

\section{O "SENTIDO" DA INDEPENDÊNCIA}

$\mathrm{N}$ ão parece exagero afirmar que o enquadramento teórico predominante e mais influente na historiografia da Independência, pelo menos desde os anos 1960, é aquele derivado da abordagem de Caio Prado Jr. Partindo de um ponto de vista marxista, ele procurou entender o "sentido" da colonização, inserindo a história do Brasil num contexto senão planetário, ao menos ocidental: a história do Brasil explicar-se-ia como um derivativo da história européia, no contexto da expansão do capitalismo comercial. Essa tese é a base das teorias da dependência. ${ }^{6}$

Quem melhor definiu a Independência a partir dessa perspectiva foram justamente Fernando Novais e Carlos Guilherme M ota. Para os professores da USP, é a subordinação do Brasil a um sistema econômico mundial unificado sob o capitalismo comercial que dá sentido ao curso da Independência:

[...] qualquer estudo que vise uma síntese compreensiva da emancipação política da América portuguesa [deve] situar o processo político da separação colônia-metrópole no contexto global de que faz parte, e que lhe dá sentido; e, só então, acompanhar o encaminhamento das forças em jogo, marcando sua peculiaridade.

Esse ponto de vista é desenvolvido tanto no ensaio "As dimensões da Independência", escrito por Novais para 1822: Dimensões, quanto no capítulo "Contexto" de A Independência 
política do Brasil (p.22-ss). Nesse diapasão, a colonização é um instrumento de "acumulação primitiva (isto é, acumulação prévia necessária à formação do capitalismo) de capital comercial nas áreas centrais do sistema)" e a Independência do Brasil seria não mais que um efeito do desmantelamento da sociedade do Antigo Regime, ou, como dizem os próprios autores, da passagem do feudalismo para o capitalismo, na longuíssima duração.

Por certo que ninguém negará a importância dessa ampla contextualização histórica. 0 desmantelamento da sociedade feudal, cuja falência do absolutismo e a crise do Antigo Regime constituem dois aspectos derradeiros, são o pano de fundo da cena histórica. Para usar a metáfora teatral, o pano de fundo enquadra, estabelece os limites em que agem os personagens, mas absolutamente não Ihes determina as falas e ações. H oje podemos afirmar tratar-se de uma derrapagem teórica procurar explicar um fenômeno eminentemente político com explicações macroestruturais de longa duração. É usar a ferramenta errada, como atirar um míssil Patriot para derrubar um pardal. Além disso, essa abordagem evidencia um caráter teleológico indisfarçável, que reponta de uma tradição marxista da história entendida como sucessão linear de modos de produção. ${ }^{8}$ A política, como ensinou Gramsci, ${ }^{9}$ é o lugar da luta dos grupos e indivíduos, onde projetos e desejos individuais e coletivos digladiam-se por estabelecer uma hegemonia. Se fôssemos buscar as razões (o sentido, por que não?) da Independência em movimentos estruturais de longa duração, poderíamos então atribuí-la à queda do império romano, precursora da formação da sociedade feudal, da qual a crise do Antigo Regime marca 0 ocaso.

Trata-se, aquela, de interpretação fundada num quadro teórico engessado, que retira do processo histórico toda cor e todo brilho das relações sociais vividas pelos agentes. Um processo eminentemente social, ideológico e político, como foi a Independência brasileira, se torna derivação de um macroprocesso econômico. O conceito de "sistema", com seus mecanismos, deságua numa estrutura rígida, como o autômato de Walter Benjamin ${ }^{10}$ ou as maquinarias com que Thompson 


\section{ironizou Althusser: ${ }^{11}$}

Eis aí as peças do antigo sistema colonial: dominação política, comércio exclusivo e trabalho compulsório. Assim se promovia a acumulação de capital no centro do sistema. Mas, ao promovê la, criam-se ao mesmo tempo as condições para a emergência final do capitalismo, isto é, para a eclosão da Revolução Industrial. E, dessa forma, o sistema colonial engendrava sua própria crise, pois o desenvolvimento do industrialismo torna-se pouco a pouco incompatível com o comércio exclusivo, com a escravidão e com a dominação política, enfim, com o antigo sistema colonial [...] A crise do antigo sistema colonial parece, portanto, ser o mecanismo de base que lastreia o fenômeno da separação das colônias [...] Trata-se, antes de tudo, de inserir o movimento de Independência no quadro da crise geral do colonialismo mercantilista. ${ }^{12}$

Entendido o funcionamento da máquina, sua "dialética", está dada a história... Assim, a partir de tal enquadramento teórico, o caráter da Independência não passa de um epifenômeno. Os processos de independência na América Latina seriam meras "vertentes do mesmo processo de reajustamento e ruptura na passagem para o capitalismo moderno, na segunda metade do setecentos e primeira metade do Oitocentos". Contido nessa definição encontra-se veladamente o pressuposto de que a Independência não foi senão um ponto no longo processo de desmantelamento do Antigo Regime europeu e do antigo sistema colonial. ${ }^{13}$

Se, por um lado, podemos aceitar sem maiores dificuldades que o planeta formava um "sistema-mundo" desde a expansão européia da Era Moderna, tal como proposto por Fernand Braudel e Immanuel Wallerstein, ${ }^{14}$ isso não deve necessariamente fazer derivar as histórias de diferentes povos do globo desse processo unilinear que é o da suposta vitória da civilização ocidental e sua afirmação econômica, política, militar e cultural sobre as partes conquistadas. No âmbito da consciência histórica e da produção historiográfica, a aceitação de tal proposição fundamenta-se na aceitação de uma master-narrative, ${ }^{15}$ justamente a daquela marcha vitoriosa de um projeto de 
humanidade, à qual todas as demais histórias estariam subsumidas.

Portanto, para sintetizar, a clássica obra coletiva organizada pelo Prof. Carlos Guilherme Mota, com o fim de escrutinar as dimensões da Independência, divide-se em duas grandes partes: uma primeira, onde são teoricamente estabelecidos os enquadramentos dentro dos quais aquele acontecimento pode e deve ser percebido e explicado. E uma segunda, cuja abordagem necessariamente local ou regional a impede de alçar qualquer vôo teórico para ser tornar, irremediavelmente, événementiele.

\section{ECOS DE OXFORD}

No evento realizado em 2003, em Oxford, o tema do seminário era a mesma Independência do Brasil. Será que a mesma? O bservando-se o teor dos textos, nem parece se tratar do mesmo assunto.

Em primeiro lugar, porque a angular de todos ali era muito menos potente. Ninguém precisou situar a Independência no processo de passagem do feudalismo para o capitalismo para analisá-la de diferentes perspectivas. Quanto à suposta "crise do antigo sistema colonial", ela foi tratada logo na segunda sessão, focada nas relações entre Portugal e Brasil na virada do 18 para o 19 ("The historical roots of Brazilian independence"). No primeiro paper dessa sessão, "The birth of two nations. The political economy of the breakdown of the Portuguese-Brazilian Empire", Dr Jorge M. Pedreira questionou abertamente a conhecida tese da suposta "crise do Antigo Sistema Colonial". De acordo com o autor, a separação entre Portugal e Brasil foi incrementada por uma mudança na forma do governo em Portugal, que por sua vez foi causada, em parte, pela residência do rei e sua corte no Rio de Janeiro desde 1808. Ao fim e ao cabo, a natureza monárquica e a continuidade dinástica do regime emergente no Brasil foram preservadas, assim como se preservou dentro do novo Estado a unidade da enorme massa territorial. Em Portugal, do ponto de vista do Prof. Pedreira, a secessão (que em termos econômicos se tornou aparente por volta de 1808) 
teve um impacto ainda muito maior que no Brasil. A crise resultante inaugurara uma época de comoções, em que o antigo império teve que dar lugar à construção de uma nova nação moderna, ficando agora reduzido quase às suas fronteiras européias.

0 argumento mais inovador do Dr. Pedreira, e o mais controverso, foi 0 questionamento da explicação da Independência brasileira baseada na "suposta crise do sistema colonial". Pedreira sustenta que a explicação da falência do império português nas Américas deve ser procurada nas circunstâncias históricas específicas - nos contextos nacionais e internacionais - nas quais ocorreu. Os historiadores têm tentado às vezes interpretar essa falência como o resultado inevitável de uma crise prolongada, causada por grandes transformações econômicas e políticas de âmbito mundial (a Revolução Industrial e as revoluções americanas e francesas). Mas, de acordo com as pesquisas do autor, não havia sequer sinal de "crise" no sistema. Ao contrário, ele nunca havia funcionado tão bem. Pedreira sustenta que a evidência para tal crise seria muito menos convincente do que amiúde se supõe. 0 grande crescimento econômico e a prosperidade comprovada do comércio marítimo sob o antigo sistema colonial põem em dúvida a própria existência de uma "crise". Falhas no sistema e sintomas de distúrbios foram grosseiramente superestimados. Pedreira argumenta que a explicação para a Independência do Brasil, quando e como ela aconteceu, deve ser encontrada nas circunstâncias históricas precisas em que ocorreu.

A rivalidade entre França e Inglaterra, as invasões francesas e a ocupação de Portugal, a fuga do rei e sua corte para o Rio de Janeiro, a suspensão inevitável do sistema colonial, a ascensão do Brasil ao status de Reino Unido a Portugal, tudo isso teria preparado o cenário para o desfecho da Independência. Esta se tornara de imediato inaceitável para amplos setores das elites portuguesas, que estavam ansiosas para retomar o controle absoluto sobre o comércio do Brasil e se ressentiam pela ingerência britânica em assuntos nacionais. 0 governo surgido da primeira revolução liberal forçou o rei a retornar a Portugal e não pôde esconder suas intenções de recuperar o poder sobre o 
Brasil. Desta maneira, ela apressou o movimento para a Independência política, que agravou a situação econômica após a suspensão do sistema "colonial".

0 debate que se seguiu foi acirrado em torno do conceito de "crise", uma vez que se levantaram argumentos favoráveis ao núcleo do conceito "de antigo sistema colonial". Alguns debatedores presentes no workshop em Oxford sustentaram que a "crise", neste contexto, deve ser relacionada a desenvolvimento e crescimento e se deveria antes discutir a extensão, duração e natureza da suposta crise do antigo sistema colonial. Não obstante, houve certo consenso em torno da necessidade de mudar o foco "das estruturas para o processo", na análise de um fato eminentemente político tal como a emancipação política brasileira.

N a mesma tarde, Dr João Pinto Furtado apresentou o paper "History makes a nation. The Inconfidência Mineira, historical criticism and dialogue with historiography", em que o autor procurou oferecer uma aproximação crítica inovadora de interpretações historiográficas consolidadas, à luz das novas perspectivas abertas por estudos recentes sobre a economia e a política de fins do século XVIII, bem como o suposto caráter insubordinado ou revolucionário de M inas Gerais.

Seu trabalho visa também a contribuir para a crítica de algumas teses correntes, nomeadamente aquelas que corroboram a existência de um projeto nacional pronto e acabado ao qual os "inconfidentes" aderiram. Atribuir um sentido intrínseca e exclusivamente nacionalista à Inconfidência Mineira, de acordo com Furtado, é resultado da formação de uma certa memória nacional, por meio do reconhecimento simbólico que tal movimento adquiriu. Situado na transição entre o Antigo Regime e a Idade Moderna, o movimento foi marcado por ambigüidades e contradições. Seus atores, ações e projetos podem ser compreendidos melhor se considerados no contexto de heterogeneidade social e econômica expressos no conteúdo político e no sentido geral do movimento. Assim percebida, a Inconfidência M ineira seria uma síntese de várias tendências e tradições com seus próprios projetos de futuro, a proposta de 
uma ordem política nova, bem como a recuperação de alguns aspectos do passado de M inas Gerais. Na opinião de Furtado, 0 movimento em Vila Rica em 1788-9 poderia melhor ser caracterizado como um tipo de "motim de acomodação" do antigo regime, antes do que uma sedição propriamente dita e menos ainda uma revolução.

O segundo dia do seminário foi aberto com sessão sobre "The Portuguese Court in Brazil (1808-21) and Brazilian independence". 0 foco foi dirigido aqui para a época de D. João VI no Rio de Janeiro. Kirsten Schultz ("The Age of Revolution and the Transfer of the Portuguese Court to Brazil") procurou situar o fenômeno da Independência no contexto atlântico da era das revoluções, onde a Independência brasileira se caracterizou com uma alternativa conservadora aos desafios republicanos à monarquia, que definiram os processos de independência nos Estados Unidos e na América espanhola e a Revolução Francesa.

$M$ uito desse conservadorismo foi atribuído pelos historiadores à transferência da corte portuguesa em 1807-8. Schultz pretendeu relativizar essa tese, examinando as maneiras pelas quais os homens de Estado portugueses e os contemporâneos que viviam no Rio de Janeiro definiram a era das revoluções; como definiram o sentido da Revolução Francesa especificamente, e como estes sentidos foram transformados com transferência da corte.

Trocando em miúdos, Schultz analisou a apropriação do ideário revolucionário pelos portugueses d'aquém e d'além mar, resgatando a cultura política da época e sua ressignificação no ambiente da América Portuguesa. Em suma, analisando as implicações das novas linguagens e práticas políticas à época da transferência da corte e da Independência brasileira, a linha básica do argumento de Schultz é que a transferência da corte marcou um ponto de inflexão nos modos pelos quais as elites portuguesas compreenderam o contexto da Revolução Francesa e seus desdobramentos. Porque a própria transferência da corte foi percebida em si como "revolucionária", a posição anteriormente defensiva assumida com relação à mudança e aos desafios políticos ao antigo regime não mais se sustentavam. Em conseqüência, os dirigentes portugueses começaram a forjar uma 
compreensão da transformação política que defendesse a monarquia e o império.

No segundo paper da mesma sessão, "On men and titles: The logic of social interactions and the shaping of elites in preindependence Brazil", analisei a fuga da família real portuguesa de Lisboa para o Rio de Janeiro em 1808. M inha hipótese, não explicitada em A corte no exílio, é a de que tal fuga significou sim uma etapa decisiva para a emancipação política brasileira. A interação entre a corte migrada e a classe superior fluminense, a qual financiou o assentamento dos adventícios, ocorreu sob a estrita observância da etiqueta social, como prescrito pela lógica da sociedade de corte portuguesa. 0 príncipe regente $D$. João desempenhou papel decisivo como o gerente do encontro entre a corte portuguesa e os capitalistas brasileiros. Na apresentação, ambos os grupos foram detalhadamente analisados, assim como o foi a importância de alguns pilares ideológicos da monarquia portuguesa, como a propriedade ancestral da liberalidade do rei, expediente decisivo para a constituição dos grupos principais no começo da luta pela Independência.

Lilia Moritz Schwarcz apresentou um paper intitulado "Illuminating parallel scenarios. The symbolic dimension of independence festivities and the payment for the Royal Library". De uma perspectiva mais antropológica, amparada em autores como Norbert Elias, Clifford Geertz, Claude Levi-Strauss e M arc Bloch, que enfatizam a eficácia política do poder simbólico, Schwarcz resgatou o contexto da Independência brasileira de dois ângulos diferentes: as festividades públicas e o alto preço que os brasileiros pagaram pela biblioteca nacional durante as negociações da Independência entre Brasil e Portugal. Schwarcz explorou as dimensões simbólicas e culturais que, de acordo com sua abordagem, foram extremamente importantes nos primeiros momentos da Independência brasileira (e de seus desdobramentos imediatos).

Schwarcz procurava compreender como, junto com atos muito pragmáticos, houve outras ações imbuídas de uma dimensão simbólica mais específica, para muito além da estrita racionalidade política. Os festivais procuravam naturalizar uma 
situação absolutamente estranha naquele contexto: uma monarquia cercada por repúblicas de todos os lados. Paralelamente, uma verdadeira batalha bibliográfica aconteceu, exatamente no momento em que se calculava o preço a ser pago pela autonomia. No fim desse processo, a biblioteca do rei permaneceu no Rio de Janeiro: o Brasil era o país mais novo, com a maior e mais antiga biblioteca da América. Foi uma espécie de prêmio usado para mostrar quão velho o Novo Mundo poderia ser.

Três ensaios constituíram o núcleo temático do seminário, ou a "Independência propriamente dita", ali entre 1821 e 1825.

Iara Lis Schiavinatto ("Questions of Governability in the foundation of Brazil as an autonomous political body (c. 17801830)") tratou da fundação do Brasil como uma entidade política autônoma, analisando as ressignificações do antigo regime português pelo assim chamado liberalismo constitucional na transição de um império luso-brasileiro para um império do Brasil. Em vez de pensar na história brasileira numa linha progressiva, da colônia à nação, ou como resultado de um discurso nacionalista, sua fala tratou da questão da fundação do Brasil como uma cultura política genuína.

Schiavinatto argumentou que alguns movimentos foram decisivos para um aumento considerável do debate político durante o processo da Independência brasileira. As questões mais diretamente exploradas foram a negociação política do pacto, as diversas noções das identidades coloniais, a autonomia relativa e as dependências entre o poder central e periférico e noções diversas de temporalidade.

No segundo ensaio dessa sessão ("The national appeal by the Constitutional Conventions in Lisbon, 1821-1822"), Márcia Berbel procurou retomar os discursos dos deputados brasileiros nas "Cortes" portuguesas entre 1821 e 1822 e avançar sua análise em três aspectos principais: 1) a diversidade dos apelos à unidade do império português-brasileiro feitos pelos deputados presentes nas Cortes; 2) as principais ações que passaram pelo congresso, reavaliando-os à luz da seguinte questão: propostas para a unidade nacional ou para a recolonização?; 3) descontentamentos pendentes em cada uma das províncias 
brasileiras em relação à política das Cortes, identificando as razões que conduziram para a reafirmação das várias independências regionais, a despeito de tal apelo à unidade.

A contribuição mais importante de Berbel diz respeito ao problema da existência de projetos "recolonizadores" dentro das Cortes de Lisboa. Berbel demonstrou que, em seu uso inicial, 0 termo se refere a determinadas provisões legais que foram aprovadas mesmo na presença dos deputados de duas províncias brasileiras, Pernambuco e Rio de Janeiro. Mostrou como as referências à política de re-colonização das Cortes foram incorporadas pelos historiadores já no século século XIX. 0 ensaio de Berbel corrobora estudos recentes sobre reclamos por unidade nacional nas Cortes (portuguesas ou espanholas), que conduziram a uma reconsideração desta explicação amplamente aceita. Tais projetos pela unidade nacional, criados com o intuito de manter a integridade do Império, incluíam a representação americana e não podiam, dessa maneira, visar a resgatar o status colonial anterior.

0 papel desempenhado pela imprensa e a cultura impressa e as lutas entre as inúmeras facções políticas no movimento para a Independência brasileira foi o tema central do ensaio "The birth of a Brazilian press and Brazil's independence, 1821-1823", apresentado por Isabel Lustosa. A autora afirmou que os primeiros jornais brasileiros independentes, fundados após a revolução constitucionalista do Porto, tiveram peso decisivo nos acontecimentos que se seguiram àquela revolta, que levou à Independência de Brasil. Entre 1808 e 1820, tudo que foi escrito no Rio de Janeiro só podia ser impresso após rigorosa censura. N este contexto, o Correio Braziliense (1808 a 1822) transformouse no único veículo usado para divulgar idéias liberais aos brasileiros, e para criticar os erros os mais gritantes da administração portuguesa - transferida para o Rio de Janeiro junto com a corte. Ao divulgar os eventos políticos mais importantes e os analisar à luz das novas idéias liberais, o Correi o Braziliense transformou-se numa referência imperativa àqueles que sonhavam com o progresso e a liberdade no Brasil. A liberdade de imprensa conquistada após a revolução portuguesa 
de 1820 permitiu que os liberais brasileiros encontrassem um canal por meio do qual pudessem expressar e divulgar suas idéias.

Todas as abordagens acima referidas remetem a temáticas surgidas com o chamado cultural turn, que incidiu diretamente na historiografia com a eclosão das chamadas "nova história cultural" e "nova história política" que, como de praxe, chegaram ao Brasil com mais de uma década de atraso. ${ }^{16}$ Todas essas questões, que praticamente constituem o núcleo problemático da atual historiografia sobre a Independência - de que os papers apresentados em Oxford são um diáfano exemplo - não estavam na ordem do dia dos historiadores no início da década de 1970 assim como a discussão sobre questões estruturais, tão caras aos historiadores do começo dos anos 1970, foi praticamente riscada da agenda contemporânea. Uma outra questão que não se levantava à época de 1822 dimensões era a de uma virtual participação popular no processo de Independência, até então serenamente tida como um processo intra-elites. Como negros e brancos pobres, escravos e libertos participaram ou não desse acontecimento?

Este assunto, em particular, é polêmico e podemos dizer que não se avançou muito nas duas últimas décadas no conhecimento do papel das classes populares - escravos, libertos, homens livres pobres - no processo de Independência. Os estudiosos da escravidão avançaram um passo. Em ensaio muito citado, publicado em 1989, João José Reis analisa a participação dos negros nas lutas pela Independência na Bahia. Para Reis, além dos tradicionais partidos políticos, outros agentes disputavam interesses nas lutas da Independência. É o caso dos escravos, que a viam como uma possibilidade de alçar sua alforria. A indeterminação posterior ao contexto turbulento da revolução do Porto, que na Bahia gerou forte reação militar ao 7 de setembro por parte das tropas portuguesas, possibilitou 0 surgimento de um cenário tal que permitiu aos escravos participarem de discussões sobre questões candentes como liberdade política. Sem dúvida, em suas pesquisas pioneiras sobre os caminhos da liberdade no Brasil escravista, João José Reis contribuiu para a abertura a outras dimensões do processo de Independência até então negligenciadas pela historiografia. ${ }^{17}$ 
No mesmo sentido avançam os resultados de pesquisa de Hendrik Kraay. ${ }^{18}$ Vou tomar seu artigo sobre o recrutamento de escravos na Bahia à época da Independência ${ }^{19}$ como pretexto para demonstrar meu ponto de vista, da dificuldade de se investigar o papel desempenhado pelas camadas populares no processo de Independência.

Kraay mostra que o recrutamento de escravos na Bahia "fora um esforço improvisado, que não foi ordenado nem regulado por decreto". O problema estava na alforria que os escravos alistados esperavam e na posição dos seus senhores diante do Estado, no sentido da expectativa de indenização. Kraay insiste na necessidade da diferenciação entre "escravo" e "liberto" na análise do recrutamento. A participação dos últimos não trazia maiores problemas. Em 1823, Pierre Labatut os recrutara. Mas...

A questão dos escravos era bem diversa. Há indícios de que, já em setembro de 1822 (antes da chegada de Labatut), patriotas pretendiam usá-los. Maria Quitéria de Jesus contou depois a M aria Dundas Graham que patriotas então queriam obrigar seu pai, um português, a contribuir com um escravo, pois não tinha filhos para dar ao exército. A resposta dele - "que interesse tem um escravo para lutar pela Independência do Brasil?" - sem dúvida refletia atitudes bem difundidas $[\ldots]^{20}$

Esse é ponto central para mim. 0 ensaio de Kraay trata com propriedade a questão de como a Independência, indiretamente, pela via do recrutamento (ou por outras vias mais sutis, como a boataria, o imaginário) mexeu com assuntos delicados como a condição dos cativos e os horizontes de liberdade que a guerra suscitara. M as a via contrária não faz parte de seu objeto, nem de outros estudos que eu conheça: em que medida a escravidão, como instituição, e os escravos, como grupo ou classe social, contribuíram para o processo de Independência do Brasil ante Portugal? Isso é muito diferente de se analisar os diferentes grupos sociais ou camadas populares à época da Independência, ou como a Independência incidiu em suas vidas. 
Mas foi o próprio Hendrik Kraay quem trouxe uma contribuição seminal ao debate em Oxford, ao discutir justamente sobre o papel desempenhado pelos escravos na Independência do Brasil. Em seu ensaio "Popular participation in Brazilian independence, with special reference to Bahia", texto de encerramento do workshop, Kraay tocou em pontos centrais do debate, chamando a atenção para 0 fato de que a nova historiografia sobre aquilo que os historiadores brasileiros chamam de "o processo de Independência" presta muito pouca atenção à participação popular no dito processo. Embora muitos patriotas falassem em nome das "tropas e do povo," o povo (e também as tropas) permaneceram por longo tempo como figurantes para a produção acadêmica sobre os eventos políticos dramáticos daqueles anos. Finalmente, a luta dos escravos pela liberdade colidia com o desejo dos milicianos pretos por um papel maior no novo império, e durante a revolta dos Periquitos de 1824, estes ajudaram a debelar aqueles.

Esses estudos pioneiros de Reis, Kraay e Luiz Geraldo Silva são representativos de como novos temas de pesquisa se foram instalando na pauta dos historiadores da Independência, sob influência do cultural turn que, por sua vez, tem sua própria dimensão histórica a ser levada em conta. Já há vinte anos, John Johnson argumentava que 0 desenvolvimento realmente significativo na escrita da história moderna da América Latina nos Estados Unidos, desde os anos 1960, fora marcado pelo envolvimento dos investigadores com um leque mais amplo de novas questões que incidem diretamente na vida cotidiana de homens e mulheres. ${ }^{21}$ Entre essas novas questões estariam: 0 crescente interesse pela história dos "despossuídos", a "black experience" (e as questões de raça) e a escravidão (em novas abordagens de tipo microanálise), a história social do trabalho e, particularmente, o crescimento dramático da história das mulheres ("um tema praticamente inexistente como tópico de pesquisa antes dos anos 70"). Outros temas viriam conquistar relevante espaço acadêmico posteriormente à análise de Johnson como, por exemplo, os estudos voltados à sexualidade (gays e lésbicas) e a questões ambientais.

Em estudo mais recente, Marshall Eakin (1998) pôde 
confirmar as predições anteriores. A tendência geral verificada por este autor para a historiografia norte-americana sobre América Latina pode, com alguma tolerância, ser extrapolada para a evolução da historiografia latino-americana - e à qual podemos também alinhar a historiografia brasileira. Segundo Eakin, pode-se dizer que nos anos 1980 imperou a história social, assim como os anos 1990 a "nova" história cultural, tendo se renovado o estudo de grupos não-elites como escravos, mulheres, índios, trabalhadores e camponeses. A influência do pósmodernismo, o chamado "linguistic turn" e os estudos póscoloniais com foco nos grupos subalternos surgiram como abordagens preponderantes. Dentro de tais contextos historiográficos amplos devemos procurar a explicação de por que, por exemplo, questões como memória, identidade, rituais, jogos de poder, linguagens e a participação de camadas subalternas foram temas ausentes da historiografia brasileira sobre Independência na virada dos anos 1960 para 1970, e por que hoje preenchem a pauta de preocupações dos historiadores nossos contemporâneos.

\section{CONSIDERAÇÕES FINAIS}

M ais de três décadas se passaram desde a publicação do clássico livro 1822 dimensões. Ao compararmos essa obra fundamental com os temas que estão hoje na pauta do dia, diagnosticamos uma guinada de orientação teórica, das análises estruturais, macroeconômicas e sociais, para outra coisa diferente, onde sobressaem temas afeitos à agenda criada a partir do cultural turn deflagrado nos anos 60, que culminou, no plano historiográfico, no posterior surgimento das novas histórias cultural e política. Esse amplo movimento intelectual irradiou-se dos centros do capitalismo para o resto do mundo, incluindo a América Latina.

A grande ampliação de objetos de investigação histórica verificável hoje entre nós, historiadores latino-americanos, se por um lado espel ha a fragmentação geral peculiar à fase de transição paradigmática iniciada no final da década de 1960, por outro 
evidencia a dependência (na falta de melhor termo) cultural da comunidade intelectual latino-americana (aí incluídos os historiadores) de cânones produzidos al hures.

Não vou entrar em maior detal he sobre tema tão vasto, mas apenas tentar esboçar uma explicação para aquela guinada que referi nas pesquisas sobre Independência nos 30 e poucos anos.

É comum a interpretação de que a década de 1960 foi marcada por uma violenta aceleração do tempo histórico, que incidiu nas formas do ser, mas também do fazer e do pensar históricos. Essa "virada" é um sintoma de uma guinada cultural maior vivida no mundo ocidental, que se revelou de forma dramática na própria concepção do escopo e dos limites das ciências humanas e sociais e envolveu um reexame crítico da racionalidade científica então vigente. ${ }^{22}$ Num contexto politicamente conturbado, marcado por contestações viscerais ao colonialismo europeu, às diferentes expressões do imperialismo econômico e cultural, pela propagação vertiginosa dos meios de comunicação em massa e por um processo crescente de encurtamento das distâncias e dos espaços, as velhas certezas que caracterizavam a razão ocidental foram radical mente abaladas. ${ }^{23}$

Como ensina Ciro Cardoso, a conseqüência lógica da crítica visceral ao velho humanismo levou, em termos epistemológicos, à chamada "morte do Homem", entendido como sujeito e objeto privilegiados do conhecimento, da qual sucederam todas as outras "mortes" importantes, que selaram 0 suposto fim da razão, da ciência, das certezas, da história, das grandes teorias e assim por diante. Mas é importantíssimo guardar que esse grande movimento se desenrolava nos pólos hegemônicos da cultura ocidental, nos países centrais da economia capitalista. Na América Latina, na mesma época (anos 60) uma outra vaga inovadora propagava-se ainda sob a égide da racionalidade moderna, nas diversas expressões da teoria da dependência, como acusava o Prof. M ota nas preliminares de seu livro.

As teorias da dependência, a despeito de todos os problemas justamente levantados e criticados por uma legião de intelectuais, foram o ponto culminante da formulação de um genuíno pensamento formulado na América Latina para explicar 
sua situação presente. 0 que aconteceu foi que, com a eclosão do fenômeno pós-estruturalista, seu potencial crítico e criativo foi praticamente esvaziado pelo impacto cultural bombástico do maio de 68, abortando as possibilidades de avanço dentro dessa linha de evolução intelectual e matando no berço o "novo paradigma" dependentista antes que ele pudesse influenciar decisi vamente os estudos históricos - e mesmo as ciências sociais como um todo. Tal fenômeno se explica pelo fato de que as teorias da dependência surgiram nos anos 1960, quando se detona a implosão dos paradigmas nas ciências sociais com 0 advento do pós-estruturalismo, que resultará no "pósmodernismo" dos anos 80 e 90, o qual, por sua vez, decretará a falência das macro-teorias e macronarrativas. Assim, no contexto da fragmentação da situação de transição paradigmática em que ainda nos encontramos, a utilidade e validade de uma teoria "macro" social e histórica - como as teorias da dependência perdeu o interesse e o sentido para o establishment acadêmico.

A persistência das teses sobre a "crise do antigo sistema colonial" nas décadas de 1980, 90 e mesmo até hoje, em pólos historiográficos como a USP, deve-se ao vigor de algumas estruturas de poder institucional e das redes de patronato e relações de endogenia delas derivadas, presentes nesses pólos, que induziram a uma situação sui generis no que tange à recepção dos novos paradigmas historiográficos oriundos do cultural turn, de modo que estes foram sendo paulatinamente recebidos, sem descartar o paradigma estrutural anterior, mas se moldando a ele para preservá-lo.

Esse movimento mais amplo que tentei esboçar acima é o vetor explicativo da mudança de perspectiva teórica no tratamento do problema "independência" desde o livro clássico do prof. M ota até hoje. Naquele quadrante, as explicações eram buscadas dentro desse paradigma macroteórico de percepção do fenômeno "independência" dentro do amplo contexto plurissecular da passagem do feudalismo ao capitalismo e de desagregação do antigo sistema colonial - de tal modo que a Independência é entendida como desdobramento de um processo macroeconômico que se desenrola no centro do 
sistema. Hoje, sob influência dos pressupostos da nova história cultural e política, novas questões, impensáveis naquele outro contexto, são postas na mesa: participação popular e inflexões de cor e raça; a difusão da cultura impressa, as formas espetaculares do poder (idéias, ideologias, imaginários, símbolos, mitos, utopias, espetáculos do poder, festas e comemorações cívicas, rituais, liturgias, paradas, desfiles) e assim por diante. Não causará espécie se vierem a surgir outros questionamentos, oriundos da mesma orientação pós-estruturalista e pós-moderna, tais como a importância das relações de gênero ou o papel de gays e lésbicas no processo de Independência.

Cabe-me deixar muito bem enfatizado que meu objetivo, aqui, foi indicar essas mudanças historiográficas (no âmbito dos estudos da independência) e esboçar uma explicação para elas, por mais generalista que essa explicação soe. Não cumpre necessariamente ao analista, ao crítico da historiografia, atribuir qualquer sinal de valor nessas mudanças. De modo que não me parece apropriado julgar qual seria "o melhor enfoque", se macroestrutural ou microanalítico, se fundado em explicações econômicas de longa duração ou em aspectos culturais. Nesse sentido, creio que uma abordagem não substitui a outra, que todas têm sua contribuição e suas deficiências específicas. E que a história da historiografia aponta para a constante superação de si. N este sentido, todos teremos dado nossa contribuição, que será, salutar e inevitavelmente, superada pelas gerações vindouras, que nós mesmos formaremos.

Porém, voltando a nosso tema, acredito que, até onde enxerga minha consciência histórica, 0 fenômeno "independência" não estará satisfatoriamente explicado enquanto persistirem abertas al gumas questões:

- Como se explica o fato de que, em meio a tantas forças sociais e políticas, a tantos projetos e anseios, foi justamente a solução monárquica, com o herdeiro português no topo, a que se sagrou vitoriosa?

- Ou seja, no contexto da era das revoluções, da crise do Antigo Regime e do sistema colonial, no contexto das revoluções de 
independência na América Latina, porque a Independência do Brasil aconteceu da forma como aconteceu?

Em minha opinião, é preciso refinar ainda mais os instrumentos, observar ainda mais ao microscópio, utilizando a imagem de Hobsbawn. Parece, pois, faltar uma abordagem mais focada na ação de indivíduos concretos, inseridos em configurações específicas, mas guiados por opções racionais indelevelmente orientadas com respeito a fins, como ensina Weber, e mesmo as mais recentes teorias da ação. Estamos falando de agentes históricos, de pessoas que pertenciam a diferentes grupos, mas que tinham cambiantes projetos e interesses, individuais e de grupo.

Senão, como se explica a aceitação pelas elites econômicas do País do projeto político das elites do Centro-Sul, que se uniram ao projeto imperial bragantino lançando o príncipe como "outorgante" da emancipação? Quais os interesses em jogo? A resposta a esta questão vai apontar para aquele estrato social que conseguiu garantir-se a construção do Estado imperial. Como ensina Richard Graham, dessa contenda, os proprietários de terras e os escravocratas brasileiros emergiram triunfantes. Deles era o novo Estado. ${ }^{24}$

MALERBA, Jurandir. The Independences of Brazil: theoretical reflections on historiographical perspectives. História, São Paulo, v.24, n.1, p.99-126, 2005.

ABSTRACT: "Brazilian Independence" as a subject matter of historical studies dates from the epoch of this historical fact itself. In this essay, one aims to underline this fundamental character of historiography that is its own historicity by means of a comparative analysis of ruling theoretical framework both three decades ago and nowadays.

KEYWORDS: Independence-Brazil; Brazilian Independence Historiography; Theory of Historiography. 


\section{NOTAS}

${ }^{1}$ Professor do Departamento de História - Unesp/Franca.CEP 14400-690. email:malerbaj@uol.com.br

Este texto constitui-se na base da palestra que proferi no seminário Independência: perspectivas, acervos e iconografia, realizado pelo MinC e Fundação Biblioteca Nacional, em Brasília, dia 1/9/2005. Tive a oportunidade de discuti-lo novamente com os alunos do Programa de Pós-graduação em História da UFPr em novembro de 2005, de cujo debate este texto muito se beneficiou.

${ }^{2}$ Esse texto encontra-se disponível no site do Centre for Brazilian Studies. Cf. MALERBA, J. Esboço crítico da recente historiografia sobre Independência do Brasil (desde c. 1980). University of Oxford, Centre for Brazilian Studies', 2003. Disponível em: Working papers series: $<<$ http://www.brazil.ox.ac.uk/workingpapers/Marlerba45.pdf $>>$.

3 Poder-se-ia objetar que a metodologia que utilizo nesta abordagem é imprópria em função do universo diminuto das obras selecionadas para comparação. A própria coletânea organizada por C. G. Mota, de acordo com a impiedosa avaliação de José Honório Rodrigues, teria valor desigual, por ser "sem unidade orgânica, e muito desequilibrado no valor da pesquisa e da contribuição”. Cf. RODRIGUES, Jose Honório. Independência: revolução e contra-revolução. Rio de Janeiro: F. Alves, 1975, 5.v (seu ensaio "Historiografia da Independência e seleção de documentos" encontra-se no volume 3 dessa obra). É verdade que houve uma verdadeira avalanche de publicações em função do "sesquicentenário" da Independência, como os de BARREIROS, Eduardo Canabrava. Itinerário da Independência. Prefácio de Pedro Calmon. Rio de Janeiro: J. Olympio, 1972. p.XxII; ou a obra monumental organizada por MONTELLO, Josué (dir.). História da Independência do Brasil. Rio de Janeiro: A Casa do Livro, 1972, 4.v. O próprio Prof. Mota já havia dado enorme contribuição ao tema da independência em outras obras suas, particularmente no Brasil em Perspectiva (São Paulo: Difel, 1968). Eu mesmo fiz um balanço desses grandes fluxos historiográficos e sua fortuna crítica MALERBA, J. Para uma História da Independência apontamentos iniciais de pesquisa. Revista do Instituto Histórico e Geográfico Brasileiro, Rio de Janeiro, ano 165, n.422, p.59-86, 2004. Porém, minha pretensão aqui hoje não é rigorosamente a de esgotar toda essa bibliografia, mas apenas a de fazer um exercício comparativo entre dois momentos historiográficos diversos. Nesse sentido, as obras comparadas assemelham-se em pontos fundamentais: são compostas de ensaios produzidos por historiadores profissionais, acadêmicos, familiarizados com o arsenal teórico e crítico mais atualizado de suas épocas. Essas características garantem, quero crer, a legitimidade deste exercício comparativo.

${ }^{4}$ MOTA, Carlos Guilherme (or.) 1822: dimensões. São Paulo: Perspectiva, 1972, 
p.11-12.

${ }^{5}$ Idem, p.10-11.

${ }^{6}$ Faço uma apresentação sucinta das teses e da influência das teorias da dependência na historiografia latino-americana em, MALERBA, J. Nuevas perspectivas y problemas de la historiografia en América Latina. Historia General de América Latina. Paris: UNESCO, 2006 [no prelo]. (v.9, Teoria y metedología en la historia de América Latina). Sobre as teorias da independência e sua influência na historiografia latino-americana, cf. HALPERIN DONGHI, Túlio. "Dependency Theory" and Latin American Historiography. Latin American Research Review, v.17, n.1, p.115-130, 1982; LOVE, Joseph L. The Origins of Dependency Analysis. Journal of Latin America Studies, v.22, n.1, p.143-168, 1990; BERGQUIST, Charles. Latin America: A Dissenting View of 'Latin American History in World Perspectives. In: International Handbook of Historical Studies: Contemporary Research and Theories. George Iggers and Harold T. Parker (ed.). Westport CT: Greenwood Press, 1970.

${ }^{7}$ Cf. NOVAIS, F. A; MOTA, C. G. A independência política do Brasil. 2 ed. São Paulo: Hucitec, 1996. [1.ed. 1985]. Grifo nosso.

8 Tradição fundada na leitura de alguns textos de Marx, em particular o Prefácio à Crítica da Economia Política. Outra tradição interpretativa, dentro do próprio marxismo, vai destacar da experiência de homens e mulheres e o papel da luta de classes como "motor" da história humana. Esta última linhagem, apurada, entre outros textos originais, do Manifesto comunista, é bem exemplificada na tradição do marxismo britânico. A literatura sobre esses pontos é monumental.

${ }^{9}$ Cf. GRAMSCI, Antonio. Quaderni del carcere. Ed. Valentino Gerratana. Turim: Einaudi, 1975.

10 Cf. BENJAMIN, Walter. Theses on the Philosophy of History. In: Illuminations. Trad. Harry Zohn. London: Fontana, 1992, p.245-255. Uma excelente interpretação das 'teses' de Benjamin em CARDOSO Jr., Hélio.Tempo e Narrativa Histórica nas 'Teses' de W. Benjamin”. In: MALERBA, J. (org.) A Velha História, método e historiografia. Campinas: Papirus, 1996, p.51-60.

${ }^{11}$ Cf. THOMPSON, E.P. The poverty of theory and other essays. London: Merlin Press, 1978.

${ }^{12}$ Cf. NOVAIS, Fernado A.; MOTA, Carlos Guilherme. Op. cit., p.22-23. Grifo nosso.

13 Tal interpretação influenciou enormemente e continua a influenciar a historiografia brasileira. Para Ana Rosa C. Silva, por exemplo, a independência não foi senão um ponto no longo processo de desmantelamento do antigo regime europeu e do antigo sistema colonial. 
Uma segunda questão, restrita ao pensamento de Bonifácio, emerge da afirmação da autora de que não apenas a Independência decorre da crise do antigo sistema colonial, mas que, sobretudo, Bonifácio tinha consciência dessa crise, e seu pensamento e projetos para o Brasil eram guiados por essa consciência. Cf. SILVA. Ana Rosa Cloclet. Construção da nação e escravidão no pensamento de José Bonifácio: 1783-1823. Campinas, 1996. Dissertação (Mestrado) - Unicamp, fl.160, 167.

${ }^{14}$ Cf. BRAUDEL, Fernand. Civilización material, economía y capitalismo. Siglos XV-XVIII. Madri: Alianza, 1985, 3.v; WALLERSTEIN, Immanuel. El moderno sistema mundial. La agricultura capitalista y los orígenes de la economía-mundo europea, el siglo XVI. México: Siglo XXI, 1979; WALLERSTEIN, Immanuel. El moderno sistema mundial II. El mercantilismo y la consolidación de la economía-mundo europea 1600-1750. México: Siglo XXI, 1984; WALLERSTEIN, Immanuel. The modern world-system III. The second era of great expansion of the capitalist world-economy, 1730-1840s. San Diego: Academic Press, 1989a.

${ }^{15}$ A bibliografia sobre o problema das master-narratives é imensa. Uma boa antologia foi reunida por ROBERTS, Geoggrey (ed.) The history and and narrative reader. London, New York: Routledge, 2001. Ver também RÜSEN, Jörn. Historiografia comparativa intercultural. In: MALERBA, Jurandir. MALERBA, J. Nuevas perspectivas y problemas de la historiografia en América Latina. Historia General de América Latina. Paris: UNESCO, 2006 [no prelo]. As críticas de historiadores e filósofos pós-modernos e pós-colonialistas tratam diretamente do assunto. Ver CROWELL, Steven G. Mixed Messages: The Heterogenity of Historical Discourse. History and Theory, v.37, Issue 2, p.220244, may, 1998; KLEIN, Derwin Lee. In search of narrative mastery: postmodernism and the people without history. History and Theory, v.34, Issue 4, p.275-298, dec., 1995; NANDY, Ashis. History's Forgotten Doubles. History and Theory. v.34, Issue 2, Theme Issue 34: World Historians and Their Critics, p.44-66, may, 1995.

${ }^{16}$ No começo dos anos 1990, começa a chegar à América Latina o influxo do movimento de renovação desse campo encetado na Europa (particularmente na França) na década anterior. Falava-se agora de uma "nova história política", revigorada pelo contato intenso com a história cultural, onde o conceito de "representação" torna-se um imperativo. Maria Helena Capelato e Eliane Dutra puderam constatar que essa linha de pesquisa sobre história das representações políticas articula temas que se expressam em idéias, ideologias, imaginários, símbolos, mitos, utopias, espetáculos do poder (festas e comemorações cívicas, rituais, liturgias, paradas, desfiles). Cf. CAPELATO, Maria Helena; DUTRA, Eliane. Representação Política. O Reconhecimento de um conceito na Historiografia Brasileira. In: CARDOSO, Ciro F; MALERBA, Jurandir (org.). Representações. Contribuição a um debate transdisciplinar. 
Campinas: Papirus, 2000.

17 REIS, João José. O jogo duro do Dois de Julho: o partido negro na Independência da Bahia. In: SILVA, Eduardo e REIS, J. J. Negociação e conflito: resistência negra no Brasil escravista. São Paulo: Cia das Letras, 1989, p.79-98.

${ }^{18}$ Cf. KRAAY, Hendrik. Race, state, and armed forces in independence-era Brazil: Bahia, 1790s-1840s. Stanford: Stanford University Press, 2002.

19 KRAAY, Hendrik. "Em outra coisa não falavam os pardos, cabras, e crioulos": o recrutamento de escravos na guerra da Independência na Bahia. Revista Brasileira de História, São Paulo, v.22, n.43, p.109-126, 2002.

${ }^{20}$ Idem, p. 112.

${ }^{21}$ Cf. JOHNSON, John. One Hundred years of Historical Writing on Modern Latin América by United States Historians. The Hispanic American Historical Review, v.65, n.4, p.745-765, nov., 1985, p.757-ss. Também SKIDMORE, Thomas E. Studying the History of Latin America: A Case of Hemispheric Convergence. Latin America Research Review, v.33, n.1, p.105-127, 1998, particularmente p.113-ss; EAKIN, Marshall C. Latin American History in the United States: From Gentlemen Scholars to Academic Specialists. The History Teacher, v.31 n.4, p.539-561, ago, 1998, particularmente p.550-561.

${ }^{22}$ Sobre a transição paradigmática nas ciências sociais cf. WALLERSTEIN, I. et al. Open the Social Sciences; report of the Gulbenkian Commission on the restructuring of Social Sciences. Stanford: Stanford University Press, 1996; SANTOS, Boaventura de S. Toward a new common Sense. Londres: Routledge \& Keagan Paul 1995; IGGERS, G. New directions on European historiography. ed. Rev. Middletown-Conn: Wesleyan University Press, 1984. Para a análise do impacto de 1968 na cultura ocidental, cf. AGUIRRE ROJAS, Carlos António. Los efectos de 1968 sobre la historiografia Occidental, La Vasija, México, n. 2: 1328, Ago-nov. 1998; WALLERSTEIN, Immanuel. 1968: revolución en el sistema mundo. Tesis e interrogantes. Estudos sociológicos, México, n.20, 1989; BRAUDEL, Fernand. Renacimiento, Reforma, 1968: revoluciones culturales de larga duración. La Jornada Semanal, México, n.226, 10/10/1993.

23 Cf. CARDOSO, Ciro Flamarion. Epistemologia pós-moderna, texto e conhecimento: a visão de um historiador. Diálogos, Maringá, v.3, n.3, p.1-28, 1999; também DOSSE, François. Histoire du Structuralisme I. Le champ du signe, 1945-1966. Paris: La Découverte, 1991; FERRY, Luc; RENAUT, Alain. La pensée 68. Essai sur l'anti-humanisme contemporain. Paris: Gallimard, 1985.

${ }^{24}$ GRAHAM, Richard. Construindo a nação no Brasil do século XIX: visões novas e antigas sobre classe, cultura e Estado. Diálogos, Maringá, v.5, 2001. http://www.dhi.uem.br/publicacoesdhi/dialogos/volume01/vol5 mesal.html

Artigo recebido em 02/2006. Aprovado em 04/2006. 